12

\title{
Влияние полярности искусственной грозовой ячейки на инициирование разряда группами модельных гидрометеоров
}

\author{
(С) А.Г. Темников, Л.Л. Черненский, А.В. Орлов, Н.Ю. Лысов, \\ О.С. Белова, И.Е. Калугина, Т.К. Герастенок, Д.С. Журавкова
}

Национальный исследовательский университет „Московский энергетический институт“

E-mail: TemnikovAG@mpei.ru

Поступило в Редакцию 26 сентября 2016 г.

Представляются результаты экспериментального исследования процессов инициирования модельными гидрометеорами разряда между искусственной грозовой ячейкой отрицательной или положительной полярности и землей. Впервые показано, что условия инициирования гидрометеорами искрового разряда между облаком и землей и его характеристики существенно зависят от полярности заряженного аэрозольного облака. Такое влияние групп гидрометеоров может проявляться при инициировании молнии „облако-земля“ в грозовом облаке и быть использовано при разработке научных основ методов искусственного инициирования молнии.

DOI: 10.21883/PJTF.2017.04.44295.16491

Решение проблемы активного воздействия на грозовые облака и управления процессами инициирования молнии становится все более актуальным в связи с возросшими требованиями к молниезащите объектов, воздействие молнии на которые может приводить к катастрофическим последствиям [1,2]. Одним из перспективных направлений искусственного инициирования молнии в грозовых облаках является введение в них аналогов крупных гидрометеоров [3,4]. Причем именно облачные гидрометеоры предполагаются сейчас одним из возможных ключевых факторов инициирования природной молнии $[5,6]$, который снова исследуется экспериментально с использованием высоковольтных установок, способных создавать сильные электрические поля [7]. При этом в применяемых экспериментальных схемах не учитывается, 


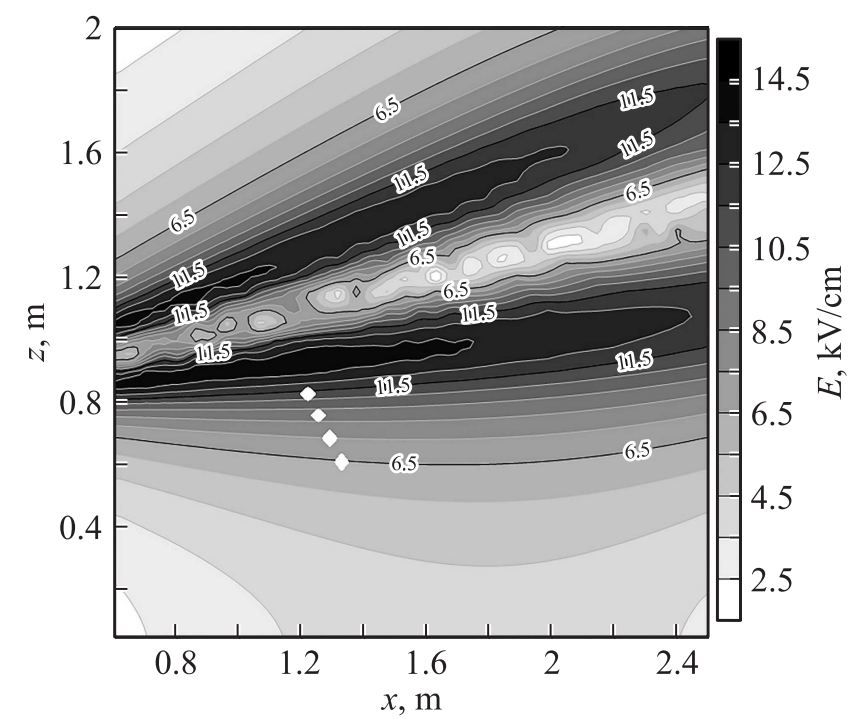

Рис. 1. Расположение группы модельных гидрометеоров и распределение напряженности электрического поля в вертикальном сечении промежутка „искусственная грозовая ячейка-земля“ при токе выноса генератора заряженного аэрозоля $110 \mu \mathrm{A}$.

что в реальном грозовом облаке гидрометеоры могут оказаться в положительно или отрицательно заряженных областях грозового облака. Использование искусственных отрицательно или положительно заряженных аэрозольных облаков может позволить выявить влияние полярности грозовой ячейки на особенности инициирования разрядных явлений гидрометеорами, находящимися внутри ячейки и вблизи ее границ. Задачей данной работы являлось определение вероятности и особенностей инициирования разряда между искусственной грозовой ячейкой отрицательной или положительной полярности и землей группой модельных гидрометеоров с целью дальнейшего возможного экстраполирования полученных результатов для решения задачи искусственного инициирования молнии.

Исследование влияния полярности искусственной грозовой ячейки на инициирование разряда между облаком и землей группами модель-

3 Письма в ЖТФ, 2017, том 43, вып. 4 
ных гидрометеоров было выполнено на экспериментальном комплексе „ГРОЗА“ [8]. Искусственная грозовая ячейка отрицательной или положительной полярности объемом в несколько кубических метров формировалась над поверхностью земли на высоте $1.0-1.5 \mathrm{~m}$. Заряд ячейки определялся током выноса $I_{\text {outlet }}$ генератора заряженного аэрозоля (ГЗА) (варьировался от 60 до $120 \mu \mathrm{A}$ ). В результате вблизи поверхности земли под облаком напряженность электрического поля составляла от 1.65 до $3.1 \mathrm{kV} / \mathrm{cm}$, вблизи нижней границы искусственной грозовой ячейки - от 10.5 до $16.0 \mathrm{kV} / \mathrm{cm}$. Группа гидрометеоров формировалась из проводящих частиц эллипсоидальной формы размером в несколько сантиметров. Гидрометеоры независимо подвешивались в промежутке „ искусственная грозовая ячейка-земля“. Верхний гидрометеор из группы находился в нижней части заряженного облака, остальные гидрометеоры располагались вблизи нижней границы ячейки. Воздушный промежуток между соседними гидрометеорами в группе составлял $2.5-2.7 \mathrm{~cm}$. В группе было четыре модельных гидрометеора. Характерное расположение группы модельных гидрометеоров и распределение напряженности электрического поля в промежутке „искусственная грозовая ячейка-земля“ показаны на рис. 1.

При экспериментах для отрицательной или положительной полярности искусственной грозовой ячейки ток выноса генератора заряженного аэрозоля менялся с шагом $10 \mu \mathrm{A}$. Для каждого варианта полярности искусственной грозовой ячейки и тока выноса ГЗА (заряда ячейки) было выполнено не менее 50 экспериментальных подходов. При каждом экспериментальном подходе заряд искусственной грозовой ячейки поддерживался на определенном уровне в течение $15 \mathrm{~s}$.

Экспериментальные исследования процессов инициирования модельными гидрометеорами разряда между искусственной грозовой ячейкой и землей показали, что условия инициирования гидрометеорами разряда между облаком и землей и его вид существенно зависят от полярности заряженного аэрозольного облака. В присутствии группы гидрометеоров наблюдались четыре варианта формирования разрядных процессов в промежутке между заряженным облаком и землей: облачные разряды (включают в себя формирование коронного разряда с отдельных гидрометеоров и искровых канальных разрядов между соседними гидрометеорами в группе), канальные разряды между облаком и землей с участием гидрометеоров $(1$ на рис. $2, a)$, канальные разряды между облаком и землей, проходящие мимо группы гидрометеоров

Письма в ЖТФ, 2017, том 43, вып. 4 


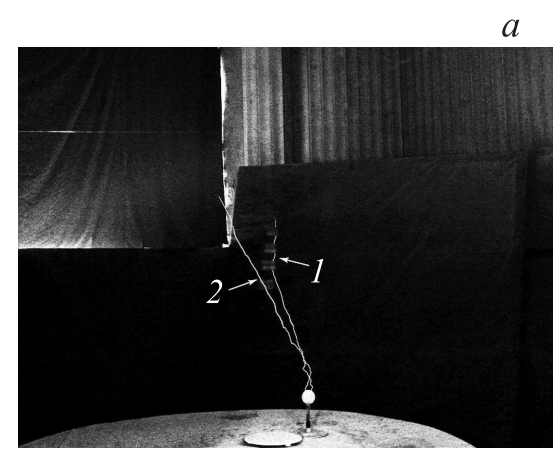

$b$

Рис. 2. Инициирование различных видов разрядов в промежутке „искусственная грозовая ячейка-земля“" массивом модельных гидрометеоров: $a-$ канальные разряды между облаком и землей с участием гидрометеоров 1 и канальные разряды между облаком и землей, проходящие мимо группы гидрометеоров $2 ; b$ - диффузные разряды между нижним гидрометеором в группе и землей.

(2 на рис. $2, a)$, диффузные разряды между нижним гидрометеором в группе и землей (рис. $2, b$ ). Первые два варианта наблюдаются при обеих полярностях искусственной грозовой ячейки. Третий вариант наблюдался только при отрицательно заряженном облаке. Четвертый вариант, наоборот, был характерен только для положительной полярности облака.

Характер изменения вероятности инициирования группой гидрометеоров различных вариантов разрядных явлений между искусственной грозовой ячейкой отрицательной или положительной полярности и землей от заряда облака (тока выноса ГЗА) представлен в таблице. Эксперименты показали существенное влияние полярности искусственной грозовой ячейки на инициирование разряда гидрометеорами. При токе выноса ГЗА более $70 \mu \mathrm{A}$ введение группы гидрометеоров вблизи ячейки положительной полярности приводило к инициированию на них разряда. При отрицательной полярности ячейки введение гидрометеоров не всегда приводило к инициированию разряда даже при токах выноса ГЗА в $90 \mu \mathrm{A}$. При больших токах выноса ГЗА другой особенностью искусственной грозовой ячейки положительной поляр-

3* Письма в ЖТФ, 2017, том 43, вып. 4 


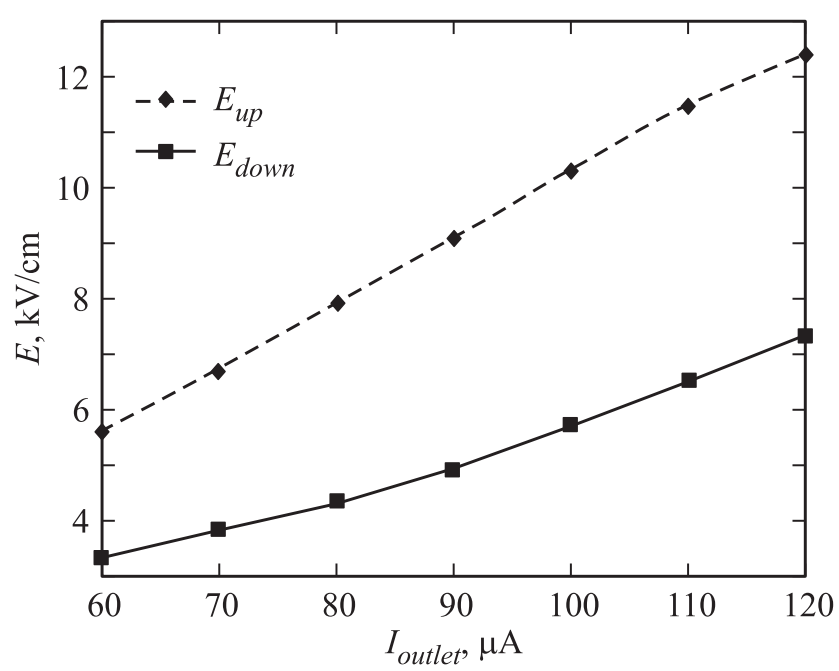

Рис. 3. Характер изменения напряженности поля искусственной грозовой ячейки в месте расположения верхнего $\left(E_{u p}\right)$ и нижнего $\left(E_{d o w n}\right)$ гидрометеора из группы модельных гидрометеоров.

ности оказалась существенная вероятность инициирования облачного разряда на группе гидрометеоров через формирование разрядов между соседними гидрометеорами в группе (от $47 \%$ при $100 \mu$ А до $20 \%$ при $120 \mu \mathrm{A})$. В целом для положительно заряженной ячейки при таких токах выноса ГЗА превалировали диффузные разряды, формирующиеся между нижним гидрометеором из группы и поверхностью земли (от 45 до $70 \%)$.

Для ячейки отрицательной полярности в этом же диапазоне токов выноса ГЗА вероятность инициирования облачных разрядов гидрометеорами составляла $7-26 \%$, и между облаком и землей превалировало формирование канальных разрядов, проходящих мимо массива гидрометеоров. Это связано с тем, что напряженность поля, создаваемого облаком у поверхности земли, достигала $4-5 \mathrm{kV} / \mathrm{cm}$ (рис. 1) и способствовала первоначальному инициированию между облаком и землей восходящего разряда, который вел к формированию главной стадии разряда без какого-либо выраженного участия гидрометеоров (65-75\% случаев). Доля канальных разрядов, инициируемых между заряженным

Письма в ЖТФ, 2017, том 43, вып. 4 
Влияние тока выноса ГЗА на вероятность инициирования группой гидрометеоров различных разрядных явлений между искусственным облаком заряженного аэрозоля отрицательной/положительной полярности и землей (в \%)

\begin{tabular}{l|c|c|c|c|c|c|c|c}
\hline \multirow{2}{*}{ Вид разрядного явления } & \multirow{2}{*}{ Полярность } & \multicolumn{6}{|c}{$I_{\text {outlet }} \mu \mathrm{A}$} \\
\cline { 3 - 8 } & & 60 & 70 & 80 & 90 & 100 & 110 & 120 \\
\hline \multirow{2}{*}{ Отсутствие разряда } & отриц. & 50.0 & 18.0 & 15.0 & 9.5 & 0.0 & 0.0 & 0.0 \\
Коронный разряд & полож. & 44.4 & 9.1 & 0.0 & 0.0 & 0.0 & 0.0. & 0.0 \\
с гидрометеоров & отриц. & 50.0 & 82.0 & 45.0 & 19.0 & 13.0 & 8.5 & 0.0 \\
Разряд между & полож. & 55.6 & 54.5 & 26.1 & 0.0 & 0.0 & 0.0 & 0.0 \\
гидрометеорами в группе & отриц. & 0.0 & 0.0 & 35.0 & 47.7 & 13.0 & 7.7 & 6.9 \\
Канальные разряды с участием & полож. & 0.0 & 36.4 & 73.9 & 81.0 & 47.0 & 48.0 & 20.0 \\
гидрометеоров & отриц. & 0.0 & 0.0 & 0.0 & 0.0 & 8.7 & 6.9 & 20.7 \\
Канальные разряды мимо & полож. & 0.0 & 0.0 & 0.0 & 0.0 & 3.0 & 7.0 & 10.0 \\
гидрометеоров & отриц. & 0.0 & 0.0 & 5.0 & 23.8 & 65.3 & 76.9 & 72.3 \\
Диффузные разряды & полож. & 0.0 & 0.0 & 0.0 & 0.0 & 0.0 & 0.0 & 0.0 \\
& отриц. & 0.0 & 0.0 & 0.0 & 0.0 & 0.0 & 0.0 & 0.0 \\
& полож. & 0.0 & 0.0 & 0.0 & 19.0 & 50.0 & 45.0 & 70.0
\end{tabular}

облаком и землей собственно группой гидрометеоров, становилась отличной от нуля при токах выноса ГЗА более $100 \mu \mathrm{A}$ (до 10 и $20 \%$ для искусственной грозовой ячейки положительной и отрицательной полярности соответственно).

Возможно, влияние полярности заряженного облака связано с характером изменения напряженности электрического поля, создаваемого искусственной грозовой ячейкой в месте расположения группы гидрометеоров (рис. 3). С увеличением тока выноса ГЗА электрическое поле в месте расположения верхних гидрометеоров возрастает до уровня, когда на них возникает коронный разряд, который частично разряжает часть заряда облака вблизи гидрометеоров и локально снижает в месте их расположения напряженность поля. В результате при положительной полярности искусственной грозовой ячейки с верхних гидрометеоров группы затруднено формирование мощных отрицательных стримеров, которые могли бы перейти в отрицательный лидер, продвигающийся в облако. С увеличением заряда облака напряженность поля вблизи нижних гидрометеоров достигает значений, достаточных для формирования положительного лидера. Поэтому группа гидроме-

Письма в ЖТФ, 2017, том 43, вып. 4 
теоров, расположенная на границе ячейки положительной полярности, приоритетно инициирует канальные разряды в сторону земли. При отрицательной полярности ячейки группа гидрометеоров провоцирует формирование канальных разрядов не только в сторону земли, но и в периферийные части заряженного облака, так как для инициирования с верхних гидрометеоров положительных лидеров требуется меньшая напряженность электрического поля, создаваемого заряженным облаком. Таким образом, эксперименты с использованием искусственной грозовой ячейки показали существенное влияние ее полярности на инициирование группами гидрометеоров разрядов между облаком и землей, которое трудно выявить с применением обычных источников высокого напряжения [7].

Исследование выполнено за счет гранта Российского научного фонда (проект № 16-19-00160).

\section{Список литературы}

[1] Lightning: Principles, Instruments and Applications. Review of Modern Lightning Research / Edited by H.D. Betz, U. Schumann, P. Laroche. Published by Springer, 2009.

[2] Apollonov V.V. // IJERD. 2012. V. 11. N 3. P. 34-50.

[3] Качурин Л.Г. Физические основы воздействия на атмосферные процессы. Л.: Гидрометеоиздат, 1990.

[4] Mazur V., Ruhnke L.H., Grzybowski S. et al. // Proc. of Int. Conf. on Atmospheric Electricity. Norman, USA, 2014. P. 180.

[5] Rakov V.A., Rachidi F. // IEEE Transactions on Electromagnetic Compatibility. 2009. V. 51. N 3. P. 428-442.

[6] Dubinova A., Rutjes C., Ebert U. et al. // Phys. Rev. Lett. 2015. V. 115. P. 015002.

[7] Mazur V., Taylor C.D., Petersen D.A. // J. Geophys. Res.: Atmospheres. 2015. V. 120. N 20. P. 10879-10889.

[8] Темников А.Г., Орлов А.В., Болотов В.Н., Ткач Ю.В. // ЖТФ. 2005. Т. 75. B. 7. C. $52-59$. 